Mavi Atlas, 5(2)/2017: 626-638.

Araştırma Makalesi | Research Article

Makale Geliş | Received: 09.09.2017

Makale Kabul | Accepted: 15.10.2017

DOI: $10.18795 /$ gumusmaviatlas. 357720

Fatih YALÇIN

Doç. Dr. | Assoc. Prof. Dr. Gümüşhane Üniversitesi, Edebiyat Fakültesi, Türk Dili ve Edebiyatı Bölümü, Gümüşhane-Türkiye Gümüşhane University, Faculty of Letters, Dep. of Turkish Language and Literature, Gümüşhane-Turkey orcid.org/0000-0001-9823-9092

fyalcin@gumushane.edu.tr

\title{
Mehmet Akif İnan’ın Poetikasında Kurucu Bir Unsur Olarak Gelenek
}

\section{Öz}

Türk edebiyatında gelenek tartışması yenileşme dönemi Türk edebiyatının başlangıcıyla birlikte ortaya çıkan ve günümüze kadar güncelliğini koruyan bir olgudur. Bu tartışma batılılaşma süreciyle ilgili olarak yapılan tartışmalarla paralel bir şekilde yürür. Batı karşısındaki fiziksel yenilginin doğal bir sonucu olarak ortaya çıkan bu süreç beraberinde günümüze kadar etkisini sürdürecek olan bir tartışmaya ve tavır alışa kaynaklık eder. Eski-yeni, geleneksel-modern gibi karşılaştırmalarla sürekli gündemde kalan bu tartışma toplumsal arada kalmışlığımızın somut göstergelerinden biri olarak ve hepsinden önemlisi kimlik oluşum sürecimizin en önemli problemi olarak varlığını korumaya devam eder. İlk şiirlerini 60'lı yıllarda kaleme alan ve 1969'da Nuri Pakdil, Rasim Özdenören ve Erdem Bayazit'la birlikte Edebiyat Dergisini 1976'da ise Cahit Zarifoğlu, Rasim Özdenören, Erdem Bayazıt, Alaeddin Özdenören ve Ersin Gürdoğan'la birlikte Mavera dergisini çıkaran İnan bu dergileri birer edebiyat okuluna dönüştürmenin gayreti içerisinde olmuştur. Gelenekten ilham alan bir yenilik ya da yeniliği ihtiva eden bir gelenek anlayışıyla şiirler yazan İnan, Divan şiiri geleneğini çağın şiir anlayışıyla buluşturarak geleneği ihmal ve tekrar etmeyen yeni ve özgün bir şiir ortaya koymuştur. Birkan'ın ifadesiyle o, "Divan şiiri nazım biçimini, hece veznini ve halk şiirini bir arada kullanma başarısını göstermiştir. Onun şiiri, bu yönüyle klasik şiirin üslup hususiyetini ve ifade kudretini modern zamana taşıyan bir şiir özelliği taşımaktadır. Bu çalışmada "Edebiyat malzemesini çağından devşirerek kendini kurar. Ve bunu yaparken dünle de ilgisini sürdürür ve geleceğe uzanır. Gövdesi çağında bir eli geçmişte, öteki eli gelecektedir edebiyatın. Geçmişle ilgisini koparamaz, çünkü çağı ile ilgilidir ve çağı ise germişin normal bir uzantısıdır; onun üstüne katlanmıştır" diyerek Divan şiiri ile günümüz arasında bir köprü kuran ve Türk şiirine yeni bir duyarlık kazandıran Mehmet Akif İnan'ın edebiyat ve gelenek konusundaki görüşleri irdelenecek ve Türk şiir geleneğinin onun şiirindeki yansımaları tespit edilecektir.

Anahtar Kelimeler: Modernizm, Gelenek, Milli Edebiyat, Şiir, Akif İnan.

\section{The Tradition as an Establishing Factor: Akif İnan's View of Tradition and its Projection in His Poetry}

\footnotetext{
Abstract

Emerging with the beginning of New Turkish literature, the discussion of tradition is a phenomenon that has kept its popularity till today. This argument proceeds in parallel with the discussion made about westernization process. Rising with the natural consequence of the physical defeat against the West, this process results in a discussion and a manner that has kept its effect up to date. This discussion- which
} 
always remains on the agenda in terms of comparisons between old-new, traditional-modern- keeps its existence as one of the most significant social dilemmas and, above all, as the most important problem of our identity formation. Inan, who penned his early poems in 1960s and published Edebiyat magazine with Nuri Pakdik, Rasim Özdenören and Erdem Beyazıt in 1969 and Mavera magazine with Cahit Zarifoğlu, Rasim Özdenören, Erdem Bayazıt, Alaeddin Özdenören and Ersin Gürdoğan in 1976, made an effort to transform these literature magazines into a school of literature. Inan wrote with the perspective of inclusive innovation inspired by the tradition. Bringing the tradition of Divan poetry together with the poetry concept of the day, Inan produced an innovative and original poetry that did not ignore and repeat the tradition. As Birkan suggests, he "achieved using verse forms, syllabic meter and folk poetry of Divan literature hand in hand". His poetry includes a characteristic that carries the specialty and expression ability of classical poetry into the modern day. The present study aims to determine the reflections of Turkish poetry tradition on his poetry and analyze the literary and traditional views of Mehmet Akif Inan who provides Turkish poetry with sensitivity and forges a link between Divan poetry and today by asserting that: "The literature itself establishes its own material by collecting it from the age. While doing this, he maintains its concern with the past and reaches the future. The body of literature exists in its age and its one hand touches the past while the other one touches the future. It cannot disrupt the relation with the past because it is interested in its age which is an ordinary extent of the past; namely, its age is folded over its past".

Keywords: Modernism, Tradition, National Literature, Poetry, Akif İnan.

Türk edebiyatında gelenek tartışması Yeni Türk edebiyatının başlangıcıyla birlikte ortaya çıkan ve günümüze kadar güncelliğini koruyan bir olgudur. Bu tartışma batılılaşma süreciyle ilgili olarak yapılan tartışmalarla paralel bir şekilde yürür. Batı karşısındaki askeri yenilgilerin doğal bir sonucu olarak ortaya çıkan bu süreç beraberinde günümüze kadar etkisini sürdürecek olan bir tartışmaya ve tavır alışa kaynaklık eder. Eski-yeni, geleneksel-modern gibi karşılaştırmalarla sürekli gündemde kalan bu tartışma toplumsal arada kalmışlığımızın en somut göstergelerinden biri olarak ve hepsinden önemlisi kimlik oluşum sürecimizin en önemli problemi olarak varlığını korumaya devam eder. Toplumu dönüştürülmesi gereken bir bütünlük, bir "muharebe meydanı" veya "fethedilmiş ülke" olarak gören yeni siyasi seçkinlerin tercih ettikleri modernleştirme programının ve bu çerçevede kendi kendilerine yükledikleri misyonun (Özipek 2011: 80) kimlik parçalanmasına maruz bıraktı̆̆ bir toplumun yaşadı̆̆ travmatik bir süreçtir bu.

Batı modernleşmesinden neredeyse yüzyıl sonra başlayan Türk modernleşmesi batıyla tamamen aynı süreci yaşamasa da benzer bir süreç ve tepkiselliği içinde barındırarak bugüne gelmiştir. Bireysel anlamda insan teki gibi toplumlar da özgüven kaybına uğrayabilir. Bu dönemde Türk toplumu da böylesi bir özgüven kaybına maruz 
kalır. Özgüven kaybı duygu ve düşünce dünyasının uçlarda hayatiyet bulması gibi sorunlara kaynaklık eder. Bu durum hem bireysel hem de toplumsal hayat açısından geçerlidir. Bu tür birey ve toplumlarda tavır alışlar radikal bir mecrada seyreder. Zihinler şirazeden çıkar; makuliyetini kaybeder. Ara renklerin kaybolduğu böylesi dönemlerde her şey varla yok, siyahla beyaz karşıtlığg ve tahammülsüzlüğü içerisinde algılanır. Bu travmatik süreç hayattın tüm alanlarını ve dolayısıyla da edebiyat alanını da doğrudan etkiler.

"Edebiyat malzemesini çağından devşirerek kendini kurar. Ve bunu yaparken dünle de ilgisini sürdürür ve geleceğe uzanır. Gövdesi çağında bir eli geçmişte, öteki eli gelecektedir edebiyatın. Geçmişle ilgisini koparamaz, çünkü çağı ile ilgilidir ve çağı ise geçmişin normal bir uzantısıdır; onun üstüne katlanmıştır” diyerek Klasik şiirimizle ile kendi çağının edebiyatı arasında bir köprü kurmaya çalışan ve Türk şiirine yeni bir duyarlılık kazandıran Mehmet Akif İnan bu travmatik sürecin etkisini yoğun bir şekilde hissettirdiği bir dönemde edebiyat dünyasına ilk adımlarını atar. İlk şiirlerini 60’1 1 yıllarda kaleme alır ve 1969'da Nuri Pakdil, Rasim Özdenören ve Erdem Bayazıt'la birlikte Edebiyat Dergisini 1976'da ise Cahit Zarifoğlu, Rasim Özdenören, Erdem Bayazıt, Alaeddin Özdenören ve Ersin Gürdoğan'la birlikte Mavera dergisini çıkararak bu dergileri birer edebiyat okuluna dönüştürmenin gayreti içerisinde olur. Akif İnan edebiyat dünyasının içinde bulunduğu durumu şu şekilde ifade eder:

$\mathrm{Bu}$ bakımdan yeni edebiyatımız, bir yandan toplumu değiştirmeyi hedef tutan devrimlerle iç içe olarak başlayan ve gelişen, öte yandan bu batılılaşmanın tesiri dışında muhtevasını milli esprimizden kendi orijinalitemizden devşiren iki ayrı hüviyet belirtir. Toplum hayatımız, dolayısıyla edebiyatımız bu iki farklı görüşün kavgasını bir gelenek olarak sürdürmektedir. Batıya dayalı olarak yapılan devrimlerle, bu devrimlerin entelektüel ekibi olan sanatçılar bir yanda, yapılması gereken devrimlerin kendi milli hususiyetimizden devşirilmesini öngören yerli düşünceye bağlı sanatçılar öte yanda, Türk edebiyatının kubbesi altında kıyasıya savaş vermişlerdir (İnan 2009a: 12).

Modernleşme sürecinde iki karşıt tavır alış arasında sıkışan ve kendine bir hayat alanı oluşturmaya çalışan edebiyat dünyası nitelikli örnekler verememe problemiyle karşı karşıya kalır. İnan'a göre bu durumun temel sebebi bu dönem sanatçılarının dayanacağı bir kökten yoksun olması daha doğru ifade edilecek olursa yüzyılların 
birikimiyle oluşmuş olan tarihsel tecrübeye/öze/geleneğe bilinçli bir şekilde sırt çevrilmesidir. Hâlbuki sanatçı millî ve yerli olmak zorundadır. Onu özgün kılacak temel özellik budur. İnan'ın ifadesiyle (2009a: 12) “millî orijinalitemize aykırı bir kaynaktan beslenen bir sanatçının kalıcı olabilmesi, o edebiyat içerisinde kendine bir yer edinebilmesi mümkün değildir. Batıya yöneldiğimizden beridir, bir kaynağa dayanmadığı için, bu gök kubbede büyük, kalıcı bir ses bırakamadan göçüp gitmişlerdir."

Akif İnan, kültürel reddiyelerin ilan edildiği tarihlerden uzunca bir süre sonra edebiyat dünyasında görünmeye başlasa da bu dönemde de gelenek hala yetimdir. Onun yetimliği sadece geleneği tamamen reddeden yenilikçilerden kaynaklanmamakta, geleneği korumak adına onu değişmez bir bütün olarak kabul ederek yaşama imkânını elinden alan katı gelenekçilerin de bu yetimlik sürecine katkısı düşünüldüğünden çok daha fazla olmaktadır. İște böyle bir edebiyat ortamında ilk olarak edebiyat dergisi ve ardından bir okula dönüşecek olan Mavera dergisi etrafından toplanan arkadaşlarıyla birlikte İnan neredeyse modernleşme tarihimizle yaşıt olan gelenek-yenilik tartışmasına farklı bir boyut kazandırmıştır. "Geçmişi ile ilişkisini kesmiş bir edebiyat, çağı ile de alâkasını koparmış demektir. Yani çağdaş da değildir, muallâktadır, gayr-1 beşeridir ve edebiyat olma niteliğinden yoksundur.” diyen İnan (2009a: 11), bu sözleriyle zamanı parçalanamaz bir bütün olarak kabul eden Yahya Kemal'le aynı noktaya vurgu yapar. $\mathrm{Bu}$ bağlamda o düşünceleriyle daha çok toplumu bir organizma olarak kabul eden, onu oluşturan din, aile, gelenek gibi temel kurumların korunmasını öngören, radikal ve devrimci değişim önerilerine karşı tedrici değişimi tercih eden, tarihten, tecrübeden bağımsız akıl yürütmeye dayalı rasyonalist siyaseti ve onunla ilişkili olarak toplum mühendisliğini reddeden bir düşünce geleneği ve bir ideoloji olarak Anglo-Amerikan muhafazakârlığına yakın durur. Devam fikri onun edebiyat anlayışının da temelini oluşturur. Toplum hayatını dünü, bugünü ve yarını ile kesintisiz bir akış içerisinde organik bir bütün olarak kabul eder ve millet hayatında kültürel bir kesintinin olabilmesinin ancak o milletin tarih sahnesinden silinmesiyle mümkün olduğunu düşünür (İnan 2009a: 11). Devam eden bir hayatta geleneği izlerini yok etmek mümkün 
değildir. Gelenek, bazen görünürlüğünü azaltarak bazen de modern hayatın ritüelleri içinde kamufle olarak varlığını devam ettirir.

Sanat eserinin millîliği üzerinde hassasiyetle duran İnan'a göre her milletin eşyaya bakışı, hayat yorumu, zevkleri, duygu yanı, farklı bir gelişme göstermiştir. Zaman her millete onun hususiyetine uygun düşen ayrı bir tarih, sanat, tefekkür, dil vermiştir. Ancak millîlik toplumla sanatçı arasında kurulmuş olan bir döngünün ürünüdür. İçindeki yetiştiği toplumun değerlerini özümseyen sanatkâr ortaya koyduğu eserlerle bu değerleri geliştirerek devam ettirir ve yine içinde bulunduğu topluma hediye eder. Bu bağlamda Akif İnan için her büyük insan, milletin varlığına, kaynağını yine kendi milletinden devşirdiği eserleriyle katkıda bulunur ve medeniyeti kuran geliştiren, işte bu katkılardır (İnan 2009a: 13). Doğal olarak milliği geleneksel edebiyat formlarının katılaştırılarak aynen devam ettirilmesi şeklinde bir görünüm arz eden, değişmeden devam etmeyi bir zorunluluk olarak gören Kıta Avrupası muhafazakârlık anlayışı ve onun edebiyatımızdaki yansımalarıyla arasına mesafe koyar.

Milletlerin kendi kimliklerini oluşturması süreci, uzun ve meşakkatli bir sürecin neticesinde ancak gerçekleşir. Bu sürece; sanat, fikir ve eylem adamları katkı sunar ve öncülük ederler. Bir taraftan millî kimliğini oluşturan milletler aynı zamanda evrensel kültüre de katkılarda bulunurlar. Böylesine zorlu bir sürecin neticesinde ve çoğu zaman ağır bedeller ödenerek kazanılmış tecrübelerin özü olarak kabul edilen geleneğe sırt çevrilmesi, onun ortadan kaldırılmaya çalışılması İnan'a göre o milleti yeni bir maceraya, zorlu bir varoluş mücadelesine sürüklemek demektir:

Kişiliğini tamamlamış; yani medeniyet içerisinde yerini kesin olarak almış, her alanda en olgun eserlerini vermiş, kısacası millet olma vasfını kazanmış bir toplumun, içinde bulunduğu bu medeni durumdan koparılarak, bir başka medeniyet dünyasına itilmesi, onun bütün varlığını hiçe saymak, bir maceraya sürüklemektir. Bizim bilhassa Tanzimat'tan beridir, toplumca uğradığımız işte böyle bir macera olmuştur (İnan 2009a: 14).

Türk milletinin Türk-İslâm medeniyetin bir üyesi olduğunu düşünen İnan için bütün tarihimiz, sanatımız, kültürümüz, folklorumuz, edebiyatımız, mimarimiz, müziğimiz hatta mutfağımız, zevklerimiz, güzel anlayışımız, geleneklerimiz bu 
medeniyet içinde teşekkül etmiştir (İnan 2009a: 14). Batının ulaştığı teknik güçle medeniyet kavramı birbirine karıştırılmamalıdır. Medeniyet, tekniği kapsayan ancak ondan ibaret olmayan çok daha kapsamlı kavramdır. Modernleşme sürecinde teknik ilerlemeyi batı medeniyetinin bir sonucu olarak gören ve doğal olarak bu teknik güce ulaşmak için aynı medeniyet dairesine girmek gerektiği yanılgısına düşen aydınlarımız, etkisi hala devam eden kimlik bunalımının içine düşmüşlerdir. İnan'a göre sanatın içinde büyüyeceği kültürel ortamını yitirmesi, bütün olarak toplumun, bir kültür ve medeniyet bunalımı içerisinde bulunduğunun ispatıdır. Bunalımsa daha çok aydınların bir şaşırması, apışması şeklinde anlaşılmalıdır. Aydının yaşadığı büyük tereddüt, inanç sarsıntısı, içinden çıkamadığı, altından kalkamadığı sorunların saldırısına uğramasıdır bunalım. Bu bir sara nöbetidir. Bir kriz halidir. Bunalan aydının bir iç dalgalanmasıdır (İnan 2009a: 19-20). Ontolojik köklerini kaybeden bir toplumun ayakta durabilmesi, yeni filizler verebilmesi mümkün değildir. Toplumun sinir uçları kabul edilen sanatkâr ve aydınların bu tür krizlerden ilk etkilenenler olması kaçınılmazdır. Doğal olarak bu travmatik sürecin ilk somut göstergelerini, gelişim ve değişim süreçlerini bu gruplar üzerinden takip etmek mümkündür.

Bir bataklığa dönüşmüş bu kültürel ortam yüzünden yerli düşünceye bağlı fikir ve sanat adamları yetişemediğini iddia eden İnan (2009a: 15), bir sanatçının yetişmesi veya bir sanat eserinin ortaya çıkmasını doğrudan içinde bulunulan medeniyetle ilişkilendirir. Ona göre her en devrimci edebiyatta bile zayıf da olsa geleneğin izlerini bulmak mümkündür (2009a: 19). Ancak önemli olan bu izlerin yeninin inşasına ilham verecek güçte olup olmamasıdır. Bu bağlamda köklü bir gelenek bir sanatkâr için muharrik bir unsur olabilirken, kriz içindeki bir medeniyet de sanatkâr üzerinde kısırlaştırıcı bir etki yapabilir. Edmun Burke'den ilham alarak söylersek sanatsal faaliyetlerine sermayesiz/geleneksiz başlayan bir sanatkârın büyük atılımlar yapabilmesi mümkün değildir. Bu bağlamda 50'li yıllardan sonra Türk edebiyatı içindeki her sanat hareketinin az veya çok, derin veya yüzeysel gelenekle ilişki kurma çabasını bir kök/sermaye arayışı olarak değerlendirebiliriz. 
Eserlerine hayat veren form ve muhtevaya ait unsurları milletin yüzyıllarca süren bir tecrübe birikimiyle inşa ettiği kültürel havzadan almayan sanatkârlar ve onların ortaya koydukları ürünlerin halkla ilişki kuramaması bu sürecin doğal bir sonucudur. İnan'a göre (2009a: 20) “Bin yıldır bağlı bulunduğumuz bir medeniyete ve onun sanat geleneğine aykırı olarak kurulmaya çalışılan bu şartlanmış sanatın milli esprimize aykırı oluşu, sanatçı ile milleti ve dolayısıyla edebiyatla okuyucuyu birbirine küstürmüştür.” $\mathrm{Bu}$ küskünlüğü ortadan kaldıracak olan şey doğru kaynaklardan beslenerek ortaya konan eserlerin sayısının arttırılmasıdır. Bunu da ancak halkın içinden çıkmış onun değerleriyle beslenmiş sanatkârlar başarabilir. Ancak İnan'a göre yabancı bir medeniyetin değerlerinin hâkim değerler haline geldiği dönemler de bu tür aydın/sanatkârların yetişmesi ancak rastlantı sonucu olabilir. Evrensel sanat esprimize bağlı bir neslin yetişememiş olması, yerli bir edebiyatın ortaya çıkmasını ve onu takip edebilecek nitelikte bir okur kitlenin oluşmasını da engellemiş oldu (İnan 2009a: 21). Bu dönem itibariyle kitapla edebiyatla ünsiyeti zayıf olan Anadolu insanının böyle bir edebiyat için talep oluşturacak güçten yoksun oluşu sanatkârı kendi okur kitlesini yaratmak gibi bir zorlukla karşı karşıya getirir. Bu bağlamda İnan ve arkadaşlarının çıkarmış oldukları dergiler aracılığıyla "bir okur kitle yaratmak" amacı taşıdıkları da rahatlikla söylenebilir.

Resmi ideolojinin nihai bir hedef olarak gösterdiği Batılılaşma fikri Türk aydınının edinmeye çalıştığı kimliğin ortak göstereni haline gelmiş aydın olmakla batılı olmak birbirine eş nitelikler olarak kabul edilmiştir. Bu durum Türk aydınında özgüven kaybına sebep olmuş, özgüven kaybı yaşayan aydının da büyük fikir ve sanat eserleri ortaya koyması imkânsız hale gelmiştir (İnan 2009a: 35-36). Akif İnan'a göre Tanzimat edebiyatının ilk nesli, edebiyatımıza şarklıca bir kültür üzerine, garplıca bir eda kazandırmanın isteği ve gayreti içerisinde, fakat bir türlü doğulu ve batılı olamamanın talihsizliğini yaşayarak, arkasında yine az çok kendisine benzeyen bir nesil bırakarak göçüp gitmiştir. Çünkü:

Medeniyet bir milletin kabiliyetinin, gücünün asırlarca seferber olarak ortaya koyduğu "nev-i şahsına münhasır" bir maddi ve manevi değerler toplamıdır. Medeniyet bir millî deha işidir. Millî deha ise, malzemesini önce milletinden, 
onun medeniyetinden devşirir. Medeniyetin mimarı nasıl insansa, insanın dehası da mensup olduğu milletin medeniyeti ile orantılıdır. Kendi manasına uygun bir medeniyet ortamı bulamayan insan veya nesilden dâhiler yetişmesi imkânsızdır (İnan 2009a: 38).

Devletin batılılaşma macerasıyla yeni edebiyatın doğuşu aynı tarihlere denk düşer. $\mathrm{Bu}$ durum hayatımıza gazetenin de girmesiyle birlikte bir sanatçı-politikacılar nesli ortaya çıkartır. Devletin yaşadığı sıkıntılar bir anlamda sanatçıları politik kulvara çekerek politize etti. Ancak belki kısa bir süre için makul karşılanacak bu durum geleneğe dönüşünce edebiyat estetik ölçülerden uzaklaşarak politik ölçülerin kıskacına girdi (İnan 2009a: 61). Ülkemizde sanatçının politikayla ilişkisi bu dönemde sanat eserinin sınırlarını zorlayacak boyutlara ulaştı. Edebiyat kanonunu oluşturan eserlerin en belirgin ölçüsü hâkim ideoloji ile kurduğu ilişki biçimi ve seviyesi olmuştur. İnan'a göre bunun en önemli sebeplerinden birisi "sarsılmış bulunan sosyal ve siyasal düzenimizin, aydın olarak herkesi ister istemez bu konu üzerinde düşünmeye, fikirlerini yaymaya ve bu fikirlerin kavgasını yapmaya zorlamasıdır (İnan 2009a: 61-62). Ziya Gökalp'in şuur devri/şiir devri ayrımında şuur devrine tekabül eden bu dönem Türk edebiyatı için özgünlüğün kaybolduğu birbirinin benzeri eserlerin hâkimiyetindeki bir durgunluk dönemi olarak okunabilir.

Akif İnan edebiyatın politik olanla ilişkisinin çoğu zaman edebiyatı asıl kimliğinden uzaklaştırdığını düşünür ve edebiyatın aktif günlük politikanın, hele onun gazeteciliğinin hamalı haline gelmesine şiddetle karşı çıkar. Ona göre edebiyat eserinin sınırlarını zorlamak pahasına fikrin ön plana çıkması doğru değildir (İnan 2009a: 62). Edebiyatın, doğrudan doğruya politik gerekçelerle tebliğ amaçlı kullanılarak araçsallaştırılmasının edebiyatı sıradanlaştırdığı için bu yanlış bakış açısı yüzünden yazılan her şeyin edebiyat olduğuna dair bir kanaat oluştu. İdeolojisiz sanat olmaz ancak ideoloji adeta çayın içinde şekerin erimesi misali verilmelidir (İnan 2009: 20). Hâlbuki gerçekte böyle olmadı. Bu durumdan en fazla şiir etkilendi. Cumhuriyetle birlikte ortaya çıkan medeniyet değiştirme çabasının ilk yankı bulduğu sahalardan biri de Türk edebiyatı olmuştur. Dünya edebiyatında olduğu gibi bizde de bu geçiş dönemi edebiyatta slogancı bir söyleyişe kaynaklık etti. Hızla irtifa kaybeden Türk edebiyatında 
elbetteki bütün olumsuz şartlara rağmen başarılı örnekler de verildi. Ancak oluşturulan bu hava içerisinde iyi örneklerin fark edilmesi ve hak ettiği değeri görmesi çok kolay olmad1. Siyasi iradenin oluşturmuş olduğu inkılap kanonunun edebiyat üzerindeki hakimiyeti kırılana kadar sessiz ve gürültüsüz bir şekilde yoluna devam eden bu örnekler sonrasında edebi hareketleri beslemiş, onlarının yürüyecekleri yolun açılmasına katkı sağlamıştır. Ahmet Haşim'in açtığı saf şiirin yolundan yürüyen İkinci Yeni hareketi ya da Necip Fazıl'ın izini takip eden şiir buna örnek gösterilebilir.

Edebiyatın özellikle şiir türünü kendine yakın hisseden İnan'a göre ortaya nitelikli bire eser koyabilmek için ciddi bir sabır ve çile gereklidir. Ancak ideolojik kavgalar bu sabrı ve çileyi ortaya koyabilecek zamanı kendi nesillerinin elinden almıştır (İnan 2009: 20). Doğal olarak ortaya çıkan edebî ürünler de ham, tam olarak işlenmemiş ürünler olmuştur. Kendisinin de bu süreçten doğrudan etkilendiğini ifade eden İnan bir dönem katı bir gelenekçi olarak yazdığ 1 birçok şiirini daha sonradan kitaplarına almadığını ifade eder. Ancak bu dönemlerinde bile o sürekli yeni şeyler denemektedir:

Divan şiirinin etkisinde aruzla gazel ve rubailer yazmaktaydım. Giderek kendimde bazı yenileşmeler oldu: Heceye yöneldim. Bu sefer de Halk şiirinin bazı örneklerini tanıdım, benimsedim ve halk şiiri ile Divan şiirinin ortalaması bir anlayışı modern örneklere kavuşturmaya çalışan bir tutum sürdürdüm. $\mathrm{Bu}$ dönemin şiirleri, o dönemin birçok sanat ve edebiyat dergilerinde yer aldı. Ve ben maalesef sonradan tamamen değiştirmiş olduğum bu anlayışın örneklerini ortaya koyarak edebiyat dünyasında göründüm. Bu görünüş benim hakkımda bazı çevrelerce bir kanaat oluşturmuştu; ben o kanaati, 1970’lere doğru tamamen değiştiren yeni şiir ortaya koymakla gidermeye çalıştım ve gidermeye katkısı olsun diye de yeni anlayışımın kuramını ifade eden yazılar yazdım (İnan 2009: 25).

$\mathrm{Bu}$ bağlamda o, yerli bir edebiyatın kurulmasının gerekliliğine inanmış ve bunu her zaman savunmuştur. Yerli/milli bir edebiyatın kurulabilmesi için ise üç temel gereklilik ortaya kor. Bunlardan ilki tarihi birikimimize yönelme mecburiyeti ikincisi dilimizin geliştirilmesi ve üçüncü ve sonucu olarak da bunlardan alınan ilhamla çağdaş biçimde söyleme mecburiyetidir (İnan 1977: 31). Eskinin ancak kaynak olarak kullanılabileceğini, kurucu bir unsur olarak değerlendirilmesi gerektiğine inanır. 
İyi/cins şiire peşinde olduğunu ifade eden İnan için cins şiirin en güzel örnekleri divan şiirimizde mevcuttur. Ancak yapılması gereken divan şiirinin aynen tekrar edilmesi değil ondan ilham alınarak yeni ürünler ortaya koymaktır. O, divan şiirinin günümüzde modernize edilerek yeni bir şiirin inşa edilebileceğini ilk iddia edenlerden biridir. Divan şiirinin çağdaş biçimde tecdit etmek gerektiğini savunmuş (İnan 2009: 20-21) ve eserleriyle de bunun ilk uygulamalarını gerçekleştirmiştir. O, şekil itibariyle divan şiiri nazım şekillerini kısmen kullansa da bunu yeni bir yorumla dile getirmeye çalışır. Onun şiiri özenle seçilmiş kelimeler, benzetmeler, söz sanatları ve imajlarla gelenekselle modernin sentezi üzerine konumlanır. Bir anlamda divan şiirimizin yaşamakta olduğunu, yerli, milli ve çağdaş bir edebiyat olduğunu ortaya koyar (Kabaklı 1964: 667). Akif İnan'sa kendi şiirini şöyle tanımlar:

Benim şiirim, Divan şiiri kültürünü almış ve o şiiri ayrıntılarına kadar tanımaya çabalayışın kişide oluşturduğu estetik kurgu ile yola çıkılarak, ama tamamen değişik imajlarla örülü ve o eski şiirimizle arasında hiçbir taklit unsuru taşımayan bir şiir. Benim bir beytimi gösteremezsiniz ki içerisinde Fuzûlî’yi, Bakî'yi, Nedim'i uzaktan andıran, hatırlatan bir söyleyiş olsun. Demek ki ben mesela bir şiir oluştururken eski şiire yenik düşenlerden olmamaya çalıştım ve eski şiiri de kendi şiirine kaynak sayıp da, kaynak gösterip de tamamen indî bir şiir oluşturanlar gibi de olmadım (İnan 2009: 21).

Eski şiire yenik düşenlerden değilim sözleriyle o, geleneğe bakış açısını da açıkça ifade eder. Onun farklılığı şiirini sadece divan şiirinden ilham alarak yeni bir imaj dünyasıyla kurmasında değil aynı zamanda kullandığı dilde de ortaya çıkar. Dil konusunda çağının yansıtıcısı olmayan, çağından ileri gitmiş veya geri düşmüş olan sanatçıların yarına kalma şansının olmadığını düşünür (İnan 2009: 22) ve kendi şiirini çağının diliyle kurar. Özellikle kelimelerin bile ideolojik kimliklere sahip olduğu bir dönemde eserlerini ortaya koyan İnan'ın kelime dağarcığında bu ideolojik dil tasnifinin etkisi görülmez. Bir kelimenin onun dağarcığında yer edinebilmesi için önemli olan hangi ideolojik grup tarafından kullanıldığı değil yaşayan Türkçe'de kendisine yer edinip edinemediği gerçeğidir. Onun bu dil tercihinde Nuri Pakdil'le birlikte çıkardıkları Edebiyat dergisi ve özellikle Pakdil'in etkisi belirgindir. Ceyhun Atuf Kansu'ya göre bir gazel yazayım, eski bir uygarlığı yenileyeyim derken ister bilinçle, ister bilinçaltıyla, halkının diliyle ve taze bir duyarlılıkla bir türkü geliştirmiştir. İçinde 
yaşadığı çağın dil, duyarlık ve uygarlığının etkisinde kalmıştır (İnan 2006: 63). Bir anlamda o çağının dil ve duyarlılığına kulak vermiş ve çağının sesi olmayı başarmıştır.

Yine kelimelerin müzikal değerleri de kelime tercihinde önemli bir belirleyicidir. (İnan 2009: 23). Şiiri bir gönül işi olarak gören İnan, şiir yazarken her kesim insana hitap etmeye çalıştığını, şiirin konusuna uygun bir müzikalitenin peşinde olduğunu vurgular (İnan 2009: 94). Oktay Çağlar'a göre o neo-klasik tarzın yaşadığı dönem itibariyle öncüsüdür ve kendine özgü bir dil anlayışı vardır. Yeni yeni söz sembolleri oluşturmak, kelimelerde biçimini bulacak olan eşyaya, ses imajı ve tonu getirmek, dile yeni bir ruh, yeni bir uyum kazandırmak onun şiirinin temel özellikleridir (Çağlar 1980: 35). Alaeddin Özdenören'e göre İnan'ın belirgin özelliklerinden biri de kelime, duygu ve düşünce tasarrufudur. Mısralarını oluştururken öyle kelimeler seçer ki dil, anlam ve duygu tam bir bütünlük oluşturur (Özdenören 1974: 3). Az sözle çok şey anlatma geleneğinin bir yansıması olan bu özellik onun şiirinin hâkim özelliklerinden biridir.

Sanatçıyı toplumun temsilcisi, şahidi ve yansıtıcısı olarak gördüğü için ona ahlaki bir sorumluluk da yükler. Çünkü o uygarlığın bizatihi inşa edicisidir. Bunu bir hammadde olarak toplumdan aldığı kaynakları devşirip ve geleceğe götürerek gerçekleştirir (İnan 2009: 97). Bu anlamda sanatkâr geleneğin hem taşıyıcısı hem de yenileyicisidir. Eğer sanatçılar bu yenileme sorumluluğunu yerine getiremezse gelenek yok olmaya mahkûm olur.

O bir anlamda sanatının özüne yerleştirdiği "gelenek”ten ilham alarak yeni bir şeyler üretebilmenin derdini çeker. Onun şiirinin gelenekle ilişkisi form düzeyinde değildir. Bu bağlamda şiirlerini Hicret ve Tenha Sözler adlı kitaplarda toplayan İnan bu şiirlerinde nazım birimi olarak çoğunlukla beyit formunu kullanmasına ve şiirlerine gazel ve kaside şeklinde adlandırmalar yapmasına rağmen bu geleneksel şiir formlarıyla ilişkisi adlandırma ve nazım birimi düzeyinde kalır. Halk şiiri formlarıyla da benzer bir ilişkisi vardır. Beyit formunda yazdığı şiirlerinde zaman zaman hece ölçüsünü kullanarak divan şiiriyle halk şiiri arasında da bir sentez arayışına gider. Bütün bu arayışlarının neticesinde kendisinden sonra gelenler için özgün bir yol açtığı 
söylenemezse de gelenek konusunda oluşturmuş olduğu duyarlılık ve geleneğin modernizasyonu konusunda eserleriyle oluşturmuş olduğu örnekler kapsamında edebiyat tarihimiz içerisindeki yerini almıştır.

\section{Sonuç}

Gelenekten ilham alan bir yenilik ya da yeniliği ihtiva eden bir gelenek anlayışıyla şiirler yazan İnan, Divan şiiri geleneğini çağın şiir anlayışıyla buluşturarak geleneği ihmal ve tekrar etmeyen yeni ve özgün bir şiir ortaya koymaya çalışmıştır. Bilkan'ın ifadesiyle (2000: 36-37) o, "Divan şiiri nazım biçimini, hece veznini ve halk şiirini bir arada kullanma başarısını göstermiştir. Onun şiiri, bu yönüyle klasik şiirin üslup hususiyetini ve ifade kudretini modern zamana taşıyan bir şiir özelliği taşımaktadır.” Geleneği kalıplaşmış bir bütün olmaktan ziyade değişerek devam eden bir kültürel öz olarak algılamıştır. O bu bakış açısıyla geleneğe modern zamanlarda da yaşayabilme imkânını sunmuş böylece gelenekle içinde yaşadığı çağ arasında bir köprü vazifesi görmüş̧ür. 


\section{KAYNAKÇA}

BİLKAN, Ali Fuat (2000). “Nabî'den Akif İnan'a Urfa Şiiri”, Mehmet Akif İnan Kitabı, Haz. Nazif Öztürk vd., İstanbul: Türkiye Yazarlar Birliği-Şanlıurfa Belediyesi Yayınları.

ÇAĞLAR, Oktay (1980). “Akif İnan'ın Şiiri”, Mavera Dergisi, Sayı: 44, Ankara.

İNAN, Akif (1977). "Edebiyatta Evrensellik ve Yerellik Konusunda Oturum", (Katılımcılar: Ersin Gündoğan, Akif İnan, Rasim Özdenören, İsmet Özel), Mavera Dergisi, 3: 11-39.

İNAN, Akif (2006). Hicret, Ankara: Eğitim Bir-Sen Yayınları.

İNAN, Akif (2006a). Tenha Sözler, Ankara: Eğitim Bir-Sen Yayınları.

İNAN, Akif (2009). Söyleşiler, Ankara: Eğitim Bir-Sen Yayınları. Yayınları.

İNAN, Akif (2009a). Edebiyat, Kültür ve Sanata Dair, Ankara: Eğitim Bir-Sen

KABAKLI, Ahmet (1974). Türk Edebiyatı Ansiklopedisi, Cilt: 3, İstanbul: Türk Edebiyatı Vakfı Yayınları.

ÖZDENÖREN, Alaeddin (1974). “Akif İnan Şiiri”, Edebiyat Dergisi, 8: 3-5.

ÖZİPEK, Bekir Berat (2011). Muhafazakârlık, İstanbul: Timaş Yayınları. 